\title{
Prevalence of Anemia among Older Adults Residing in the Coastal and Andes Mountains in Ecuador: Results of the SABE Survey
}

\author{
Carlos H. Orces \\ Laredo Medical Center, Department of Medicine, 1700 East Saunders, Laredo, TX 78041, USA \\ Correspondence should be addressed to Carlos H. Orces; corces07@yahoo.com
}

Received 10 December 2016; Revised 29 January 2017; Accepted 6 February 2017; Published 21 February 2017

Academic Editor: Francesc Formiga

Copyright (c) 2017 Carlos H. Orces. This is an open access article distributed under the Creative Commons Attribution License, which permits unrestricted use, distribution, and reproduction in any medium, provided the original work is properly cited.

Objectives. To estimate the prevalence of anemia and its determinants among older adults in Ecuador. Methods. The present study was based on data from the National Survey of Health, Wellbeing, and Aging. Hemoglobin concentrations were adjusted by participants' smoking status and altitude of residence, and anemia was defined according to the World Health Organization criteria $(<12 \mathrm{~g} / \mathrm{dL}$ in women and $<13 \mathrm{~g} / \mathrm{dL}$ in men). Gender-specific logistic regression models were used to examine the association between demographic and health characteristics and anemia. Results. A total of 2,372 subjects with a mean age of 71.8 (SD 8.2) years had their hemoglobin measured, representing an estimated 1.1 million older adults. The crude prevalence of anemia was $20.0 \%$ in women and $25.2 \%$ in men. However, higher anemia prevalence rates were seen with advancing age among black women and subjects residing in the urban coast. Likewise, certain health conditions such as hypoalbuminemia, cancer in men, chronic kidney disease, iron deficiency, and low grade inflammation were associated with increased odds of having anemia. Conclusions. Anemia is a prevalent condition among older adults in Ecuador. Moreover, further research is needed to examine the association between anemia and adverse health-related outcomes among older Ecuadorians.

\section{Introduction}

Anemia is a common medical disorder in older adults associated with increased risk of functional impairment, hospitalization, and mortality $[1,2]$. In general, the prevalence of anemia increases with advancing age and is higher among men and black populations [3]. Gaskell et al. reported that the mean prevalence of anemia among older adults in developed countries was $12 \%$ in community-dwelling older adults, $40 \%$ in hospital admissions, and $47 \%$ in nursing homes residents [4]. Previous studies have documented that the etiology of anemia in older adults appears to be multifactorial, with nutritional anemias, chronic kidney disease, and chronic inflammation found in two-thirds of the cases and unexplained anemia of aging in one-third of the cases $[3,5]$.

While the prevalence of anemia has been described in children and women of reproductive age in Ecuador, there is scarce epidemiological data about this condition in older adults [6]. In the 1980s, a study conducted by Cañizares et al. described that the crude prevalence of anemia was $21 \%$ among 2,652 subjects aged 2 to 75 years in Ecuador. Notably, the prevalence of anemia differed considerably according to areas of the country. In fact, $30.2 \%$ of subjects residing in rural areas were classified as having anemia as compared with $4.1 \%$ of those from urban areas of the country [7]. Moreover, life expectancy has gradually increased in Ecuador over the past decades. For instance, Ecuadorians were expected to live 64.6 years in $1980-1985$ and will reach 78.3 years by $2025-2030$ [8]. These demographic changes may increase considerably the number of individuals at risk for anemia in the country. Therefore, this study aimed to estimate the prevalence of anemia in a nationally representative sample of adults aged 60 years and older.

\section{Material and Methods}

The present study was based on data from participants in the first National Survey of Health, Wellbeing, and Aging 
(Encuesta Nacional de Salud, Bienestar, y Envejecimiento) conducted between 2009 and 2010. This survey is a probability sample of households with a least one person aged 60 years or older residing in the Andes Mountains and coastal regions of Ecuador. In the primary sampling stage, a total of 317 sectors from rural areas $(<2,000$ inhabitants) and 547 sectors from urban areas of the country were selected from the 2001 population Census cartography. In the secondary sampling stage, 18 households within each sector were randomly selected based on the assumption that at least one person aged 60 years or older lived in $24 \%$ and $23 \%$ of the households along the coast and Andes Mountains region, respectively. Between April and August 2010, a total of 2,375 participants underwent biochemical evaluation to determine their hemoglobin concentration. Survey methodology, including operation manuals, is publicly available [9].

2.1. Characteristics of Participants. Age and sex were selfreported. The race of participants was classified according to the following question. "Do you consider yourself to be White, Black, Mestizo, Mulatto, or Indigenous?" Body height in centimeters and weight in kilograms were measured and the body mass index was calculated $\left(\mathrm{kg} / \mathrm{m}^{2}\right)$. Subjects also reported their region (coast versus Andes Mountains) and area of residence (urban versus rural). Literacy was defined by answering affirmatively to the question "Can you write and read a message?" Smoking status was classified as current, former, and never. Self-reported health was grouped as excellent to good and fair to poor. The following activities of daily living (ADLs) were included in the present study: walking across a room, dressing, bathing, eating, getting in and out of bed, and using the toilet. Those participants who needed help or were unable to perform one or more of the ADLs as a result of health problems were considered functionally impaired. Cognitive status was evaluated by the abbreviated Mini Mental State Examination (MMSE). This modified MMSE was developed by Icaza and Albala to identify the MMSE questions that could best explain cognitive deterioration. The abbreviated MMSE was developed with nine variables instead of the 19 original MMSE variables. A cut-off point of 12 or less was defined to identify people with cognitive impairment [10]. Subjects were defined as having diabetes if they had been previously diagnosed by a physician with this condition or if fasting plasma glucose was $\geq 126 \mathrm{mg} / \mathrm{dL}$ [11]. Moreover, the following physician-diagnosed chronic conditions were self-reported: cancer, chronic obstructive pulmonary disease (COPD), heart disease, and arthritis.

2.2. Laboratory Data. Laboratory data collected in the SABE survey were analyzed at NetLab (Quito, Ecuador). Hemoglobin concentrations were measured with an automated blood cell counter. Serum ferritin and vitamin $B_{12}$ levels were determined by using the heterogeneous immunoassay method. High sensitive C-reactive protein (CRP) levels were calculated with automated turbidimetry and serum albumin and creatinine levels were measured by using automated photometry.
2.3. Definition of Anemia. Hemoglobin concentrations were adjusted by participants' smoking status and altitude of residence as recommended by the World Health Organization (WHO). Subsequently, anemia was defined by the WHO criteria as a hemoglobin concentration $<13 \mathrm{~g} / \mathrm{dL}$ in men and $<12 \mathrm{~g} / \mathrm{dL}$ in women [12]. The mean red blood cell corpuscular volume (MCV) was classified as microcytic, normocytic, and macrocytic according to MCV levels < $80 \mathrm{fl}$, 80-100 fl, and $>100$ fl, respectively [13].

Ferritin, a marker of iron storage may be spuriously elevated in inflammatory conditions. Therefore a ferritin cutoff of $45 \mathrm{ng} / \mathrm{mL}$ has a higher sensitivity for iron deficiency anemia in older adults [14]. On the contrary, a serum ferritin level $>200 \mathrm{ng} / \mathrm{mL}$ serves to confirm that anemia is not related to iron deficiency $[15,16]$. Consequently, older adults with these ferritin cut-off levels were classified as having iron deficiency anemia and anemia of chronic disease, respectively. Creatinine clearance $(\mathrm{CrCl})$ was calculated according to the Cockroft-Gault equation and subjects with a $\mathrm{CrCl}$ $<30 \mathrm{~mL} / \mathrm{min}$ were classified as having anemia of chronic kidney disease $[3,17]$. In the present analysis, a CRP level $\geq$ $5 \mathrm{mg} / \mathrm{L}$ was the cut-off used to define low grade inflammation [18]. Vitamin $B_{12}$ deficiency was defined as serum $B_{12}$ levels $<200 \mathrm{pg} / \mathrm{mL}$ and hypoalbuminemia as a serum albumin concentration $<3.5 \mathrm{~g} / \mathrm{dL}[3,19]$.

2.4. Statistical Analysis. Chi-square for categorical variables and $t$-test for continuous variables were used to compare the characteristics of the participants by gender. The crude prevalence of anemia stratified by sociodemographic and health characteristics of participants and the MCV distribution according to selected causes of anemia were presented as percentages. Moreover, gender-specific logistic regression models adjusted for age, race, residence, literacy, and smoking status were created to examine the associations between demographic characteristics and health status of the participants and anemia. Results of the multivariate model are presented as odds ratios (OR) with their 95\% confidence intervals (95\% CI). All analyses used sample weights to account for the complex survey design and to report anemia prevalence nationwide. Statistical analyses were performed using SPSS, version 17 software (SPSS Inc., Chicago, IL).

\section{Results}

A total of 2,372 subjects with a mean age of 71.8 (SD 8.2) years had their hemoglobin measured, representing an estimated 1.1 million older adults residing in the coastal and Andes Mountains regions in Ecuador. As shown in Table 1, the age, area of residency, and race of participants were similarly distributed by gender. In general, higher proportions of men were smokers, literate, and reported good to excellent health. In contrast, women had higher rates of obesity, ADL's limitations, cognitive impairment, and comorbidities. Laboratory data revealed no significant gender differences regarding CRP, albumin, and ferritin concentrations. However, vitamin $\mathrm{B}_{12}$ levels were considerably lower among men. As shown in Figure 1, women tended to have lower 
TABLE 1: Demographic and health characteristics of participants in the SABE survey.

\begin{tabular}{|c|c|c|c|}
\hline & $\begin{array}{c}\text { Men } \\
(n=1,065)\end{array}$ & $\begin{array}{c}\text { Women } \\
(n=1,307)\end{array}$ & $P$ value \\
\hline Age groups (years), $\%$ & & & .480 \\
\hline $60-69$ & 47.5 & 46.2 & \\
\hline $70-79$ & 31.6 & 34.5 & \\
\hline$\geq 80$ & 20.9 & 19.3 & \\
\hline Race, \% & & & .881 \\
\hline Indigenous & 10.0 & 11.1 & \\
\hline Black & 3.8 & 3.4 & \\
\hline Mestizo & 70.6 & 69.1 & \\
\hline Mulatto & 3.8 & 3.3 & \\
\hline White & 11.8 & 13.1 & \\
\hline Area of residency, $\%$ & & & .149 \\
\hline Urban Andes Mountains & 28.3 & 30.8 & \\
\hline Urban coast & 36.1 & 37.5 & \\
\hline Rural Andes Mountains & 20.2 & 20.3 & \\
\hline Rural coast & 15.4 & 11.4 & \\
\hline Literacy, \% & 76.7 & 64.7 & $<.0001$ \\
\hline Smoking, \% & & & $<.0001$ \\
\hline Current & 20.5 & 3.3 & \\
\hline Former & 49.1 & 12.4 & \\
\hline Never & 30.4 & 84.3 & \\
\hline BMI $\left(\mathrm{kg} / \mathrm{m}^{2}\right), \%$ & & & $<.0001$ \\
\hline Underweight & 2.3 & 2.0 & \\
\hline Normal & 49.7 & 32.9 & \\
\hline Overweight & 37.8 & 38.5 & \\
\hline Obesity & 10.2 & 26.6 & \\
\hline Self-reported health, \% & & & $<.0001$ \\
\hline Excellent to good & 30.1 & 20.2 & \\
\hline Fair to poor & 69.9 & 79.8 & \\
\hline ADL's limitations, $\%$ & 22.9 & 29.5 & $<.005$ \\
\hline Cognitive impairment, \% & 16.6 & 25.9 & $<.0001$ \\
\hline \multicolumn{4}{|l|}{ Comorbidities, \% } \\
\hline Diabetes & 13.2 & 19.6 & $<.005$ \\
\hline Cancer & 2.2 & 3.5 & .117 \\
\hline COPD & 6.5 & 9.7 & .032 \\
\hline Heart disease & 12.2 & 15.8 & .086 \\
\hline Arthritis & 20.6 & 43.0 & $<.0001$ \\
\hline Number of comorbidities, $\%$ & & & $<.0001$ \\
\hline 0 & 58.2 & 37.3 & \\
\hline 1 & 31.5 & 39.9 & \\
\hline$\geq 2$ & 10.3 & 22.8 & \\
\hline CRP, mg/L (SD) & $4.9(8.9)$ & $5.1(9.0)$ & .652 \\
\hline Creatinine clearance $\mathrm{mL} / \mathrm{min}(\mathrm{SD})$ & $66.2(20.5)$ & $66.6(23.4)$ & .629 \\
\hline Albumin, g/dL (SD) & $4.3(0.3)$ & $4.3(0.3)$ & .950 \\
\hline Vitamin $\mathrm{B}_{12}, \mathrm{ng} / \mathrm{mL}(\mathrm{SD})$ & $423.9(234.6)$ & $527.7(261.6)$ & $<.0001$ \\
\hline Ferritin, ng/mL (SD) & $172.5(164.5)$ & $165.9(159.0)$ & .325 \\
\hline
\end{tabular}




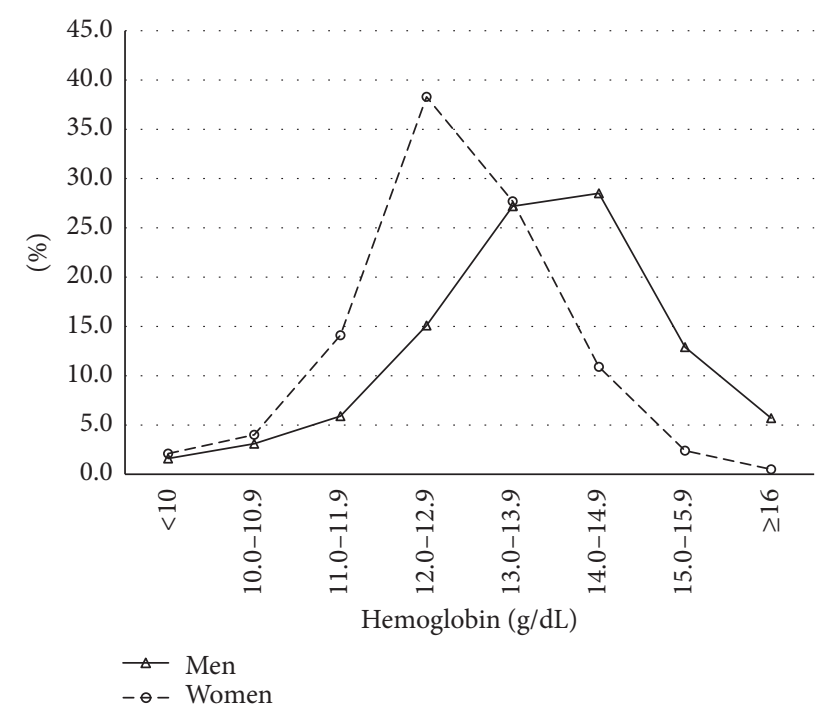

Figure 1: Hemoglobin concentrations among older adults in Ecuador, SABE II survey.

hemoglobin concentrations than those in men. For instance, $58.5 \%$ of women had hemoglobin concentrations less than $13 \mathrm{~g} / \mathrm{dL}$ as compared with $25.2 \%$ in men. However, only $2.1 \%$ and $1.6 \%$ of women and men had hemoglobin levels less than $10 \mathrm{~g} / \mathrm{dL}$, respectively.

Overall, $20.0 \%$ of women aged 60 years and older were defined as having anemia in Ecuador. Nevertheless, the prevalence of anemia among women was particularly increased in blacks and residents from the urban coast. Moreover, subjects with certain health conditions such as being underweight, chronic kidney disease, hypoalbuminemia, and iron deficiency had significant higher anemia prevalence rates. After adjustment for potential confounders, hypoalbuminemia, chronic kidney disease, being underweight, and iron deficiency were variables independently associated with 5.1-, 4.4-, 2.4-, and 2.1-fold increased odds of having anemia among older women, respectively (Table 2 ).

Anemia was prevalent in $25.2 \%$ of older men in Ecuador. Moreover, the prevalence of anemia in men increased with advancing age and was higher among those residing in the urban coast as compared with residents from other areas of the country. Likewise, subjects with hypoalbuminemia, those diagnosed with cancer, and participants defined as having chronic kidney disease, iron deficiency, and low grade inflammation had higher prevalence of anemia than those who did not. Notably, after adjustment for covariates, older men with hypoalbuminemia and those diagnosed with cancer were 6.8 and 6.5 times more likely to have anemia as compared with those without hypoalbuminemia, respectively (Table 3).

Figure 2 shows the distribution of nutritional and nonnutritional causes of anemia in older Ecuadorians. Among nutritional anemias, iron deficiency was the leading cause of anemia in $21.8 \%$ of men and $16.3 \%$ of women, whereas $13.5 \%$ of men and $6.6 \%$ of women had low vitamin $B_{12}$ concentrations. Although chronic kidney disease was associated with increased odds of having anemia in both genders,

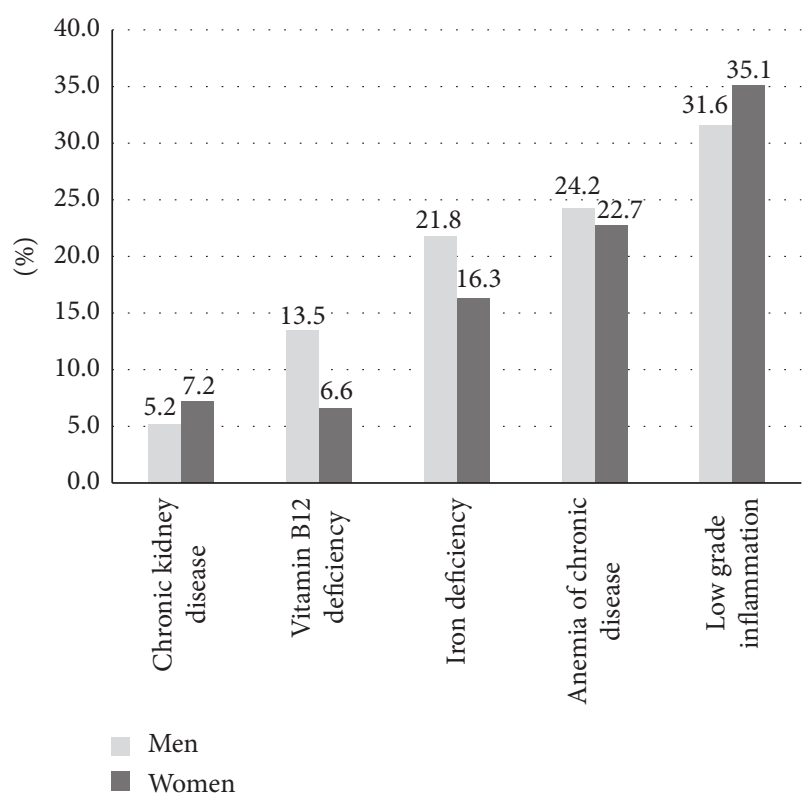

FIGURE 2: Selected causes of anemia among older adults in Ecuador, SABE survey.

only $5.2 \%$ of men and $7.2 \%$ of women were classified as having anemia of chronic kidney disease. Of interest, $24.2 \%$ of men and $22.7 \%$ of women had ferritin levels $>200 \mathrm{ng} / \mathrm{mL}$, which is highly suggestive of anemia of chronic disease. Of relevance, one-third of older adults with anemia had evidence of low grade inflammation. Table 4 shows the MCV distribution among older adults with anemia in Ecuador. In general, $88 \%$ of subjects with anemia had a normal MCV index. In general, normocytic anemia was predominantly seen in participants with kidney disease, chronic disease, and low grade inflammation. Moreover, $13.9 \%$ of men and $14.7 \%$ of women with iron deficiency anemia had evidence of microcytosis. On the contrary, a macrocytic morphology was present in only $3.1 \%$ of subjects with vitamin $B_{12}$ deficiency.

\section{Discussion}

The present results indicate that anemia represents a moderate public health problem among older adults in Ecuador according to the WHO criteria (prevalence from $20.0 \%$ to $39.9 \%$ ) [12]. Overall, one in five subjects aged 60 years and older was defined as having anemia in Ecuador. Moreover, increased anemia prevalence rates were predominantly seen with advancing age, in men, black women, and subjects residing in the urban coast. Interestingly, the geographic distribution of anemia found in the present study contrast with those results previously reported by Cañizares et al. in the 1980s in which a significant higher prevalence of anemia was described in the rural areas of the country [7]. It may be postulated that the increased prevalence of anemia among older adults in urban areas of the country may be explained by changes in the demographic distribution of the population over time. For instance, the percentage of adults aged 65 years and older who lived in the urban areas of the country 
TABLE 2: Prevalence of anemia among older women in Ecuador.

\begin{tabular}{|c|c|c|}
\hline Characteristics & Crude prevalence & OR $(95 \% \mathrm{CI})^{*}$ \\
\hline \multicolumn{3}{|l|}{ Age groups (years), \% } \\
\hline $60-69$ & $17.8(14.0,22.2)$ & 1.00 \\
\hline $70-79$ & $20.5(16.5,25.3)$ & $1.17(1.15,1.19)$ \\
\hline$\geq 80$ & $24.1(18.7,30.5)$ & $1.37(1.35,1.40)$ \\
\hline \multicolumn{3}{|l|}{ Race, $\%$} \\
\hline Indigenous & $19.0(11.6,29.7)$ & $0.69(0.68,0.71)$ \\
\hline Black & $42.4(24.4,62.7)$ & $2.19(2.12,2.27)$ \\
\hline Mestizo & $17.8(14.9,21.1)$ & $0.66(0.64,0.67)$ \\
\hline Mulatto & $24.5(11.5,44.6)$ & $0.91(0.87,0.94)$ \\
\hline White & $25.3(18.3,33.8)$ & 1.00 \\
\hline \multicolumn{3}{|l|}{ Area of residency, $\%$} \\
\hline Urban Andes Mountains & $18.4(14.3,23.4)$ & $1.58(1.54,1.62)$ \\
\hline Urban coast & $22.5(18.3,27.3)$ & $1.94(1.89,1.99)$ \\
\hline Rural Andes Mountains & $20.8(15.0,28.1)$ & $1.67(1.63,1.72)$ \\
\hline Rural coast & $14.2(9.1,21.6)$ & 1.00 \\
\hline \multicolumn{3}{|l|}{ Literacy, \% } \\
\hline Yes & $19.5(16.6,22.7)$ & 1.00 \\
\hline No & $20.8(16.2,26.2)$ & $1.09(1.08,1.11)$ \\
\hline \multicolumn{3}{|l|}{ Smoking, \% } \\
\hline Current & $32.8(16.7,54.2)$ & $1.80(1.75,1.86)$ \\
\hline Former & $19.6(13.4,27.8)$ & $0.99(0.97,1.01)$ \\
\hline Never & $19.5(16.7,22.5)$ & 1.00 \\
\hline \multicolumn{3}{|l|}{ BMI $\left(\mathrm{kg} / \mathrm{m}^{2}\right), \%$} \\
\hline Underweight & $34.5(19.1,54.1)$ & $2.41(2.31,2.51)$ \\
\hline Normal & $28.5(23.0,34.6)$ & $2.14(2.10,2.18)$ \\
\hline Overweight & $14.9(11.5,19.0)$ & $0.96(0.94,0.98)$ \\
\hline Obesity & $16.1(12.2,21.0)$ & 1.00 \\
\hline \multicolumn{3}{|l|}{ Self-reported health, \% } \\
\hline Excellent to good & $13.1(9.1,18.4)$ & 1.00 \\
\hline Fair to poor & $21.8(18.8,25.1)$ & $1.97(1.93,2.00)$ \\
\hline \multicolumn{3}{|l|}{ ADL's limitations, $\%$} \\
\hline Yes & $24.0(19.2,29.6)$ & $1.43(1.41,1.45)$ \\
\hline No & $18.3(15.4,21.5)$ & 1.00 \\
\hline \multicolumn{3}{|l|}{ Cognitive impairment, \% } \\
\hline Yes & $24.3(18.1,31.7)$ & $1.44(1.42,1.47)$ \\
\hline No & $18.4(15.6,21.5)$ & 1.00 \\
\hline \multicolumn{3}{|l|}{ Diabetes } \\
\hline Yes & $22.6(16.9,29.4)$ & $1.25(1.24,1.27)$ \\
\hline No & $19.3(16.5,22.4)$ & 1.00 \\
\hline \multicolumn{3}{|l|}{ Cancer, \% } \\
\hline Yes & $21.0(10.7,37.0)$ & $1.15(1.13,1.19)$ \\
\hline No & $20.0(18.1,23.7)$ & 1.00 \\
\hline \multicolumn{3}{|l|}{ COPD, \% } \\
\hline Yes & $13.0(6.0,26.1)$ & $0.54(0.52,0.55)$ \\
\hline No & $20.7(18.1,23.7)$ & 1.00 \\
\hline \multicolumn{3}{|l|}{ Heart disease, $\%$} \\
\hline Yes & $22.9(15.5,32.5)$ & $1.27(1.25,1.29)$ \\
\hline No & $19.4(16.8,22.2)$ & 1.00 \\
\hline
\end{tabular}


TABLE 2: Continued.

\begin{tabular}{|c|c|c|}
\hline Characteristics & Crude prevalence & OR $(95 \% \mathrm{CI})^{*}$ \\
\hline \multicolumn{3}{|l|}{ Arthritis, \% } \\
\hline Yes & $22.3(18.1,27.2)$ & $1.52(1.50,1.54)$ \\
\hline No & $18.4(15.3,21.8)$ & 1.00 \\
\hline \multicolumn{3}{|l|}{$\mathrm{CRP}(\mathrm{mg} / \mathrm{L}), \%$} \\
\hline$<5$ & $17.5(14.7,20.7)$ & 1.00 \\
\hline$\geq 5$ & $26.8(21.4,33.0)$ & $1.69(1.67,1.72)$ \\
\hline \multicolumn{3}{|c|}{ Creatinine clearance, $\%$} \\
\hline$\geq 30 \mathrm{~mL} / \mathrm{min}$ & $19.0(16.4,21.8)$ & 1.00 \\
\hline$<30 \mathrm{~mL} / \mathrm{min}$ & $57.2(36.7,75.5)$ & $4.44(4.30,4.59)$ \\
\hline \multicolumn{3}{|c|}{ Albumin (g/dL), \% } \\
\hline$\geq 3.5$ & $19.0(16.5,21.8)$ & 1.00 \\
\hline$<3.5$ & $56.0(23.2,84.3)$ & $5.01(4.85,5.18)$ \\
\hline \multicolumn{3}{|c|}{ Vitamin $B_{12}(\mathrm{ng} / \mathrm{mL}), \%$} \\
\hline$\geq 200$ & $20.1(17.4,23.0)$ & 1.00 \\
\hline$<200$ & $18.4(11.4,28.2)$ & $0.87(0.85,0.89)$ \\
\hline \multicolumn{3}{|c|}{ Ferritin (ng/mL), \% } \\
\hline$<45$ & $34.5(25.1,45.2)$ & $2.17(2.13,2.21)$ \\
\hline$\geq 45$ & $18.4(15.9,21.3)$ & 1.00 \\
\hline \multicolumn{3}{|c|}{ Ferritin (ng/mL), \% } \\
\hline$\leq 200$ & $20.4(17.6,23.6)$ & 1.00 \\
\hline$>200$ & $18.5(13.5,24.8)$ & $0.84(0.83,0.86)$ \\
\hline
\end{tabular}

* Adjusted for age, race, area of residency, literacy, and smoking status.

increased from $4.3 \%$ in 1980 to $5.7 \%$ in 2010 . Similarly, the aging index in the urban areas increased from 14.5 to 28.2 per 100 persons during the same period of time [8].

Notably, up to $42.0 \%$ of older black women were found to be anemic in Ecuador. This finding may be associated with an increased prevalence of hemoglobin variants in Afro-Ecuadorians. Indeed, a recent study reported that $22.0 \%$ of Afro-Ecuadorians from the province of Imbabura had a hemoglobin variant. Of these, hemoglobin $S$ was the most frequently reported variant representing $14.0 \%$ of the cases. Moreover, it appears that the prevalence of hemoglobinopathies in Ecuador is higher than that reported in other Latin America countries [20]. Consistent with the present findings, prior studies have demonstrated lower hemoglobin levels among blacks of all ages even after accounting for comorbidities, behavioral risk factors, nutritional intake, and iron status $[3,21]$.

In Ecuador, older adults had higher anemia prevalence rates as compared with those previously described among older adults in the United States $(10.6 \%)$, the Chianti area in Italy (11.3\%), and Mexico (13.9\%) [3, 22, 23]. Likewise, a recent population-based study conducted among older adults in Latin America reported lower anemia prevalence rates in Cuba (19.2\%) and Venezuela (9.8\%). On the contrary, up to $37.3 \%$ and $32.1 \%$ of older adults in Dominican Republic and Puerto Rico were classified as having anemia, respectively [24]. The present results indicate that the prevalence of anemia in older Ecuadorians is comparable to that recently described among subjects aged 65 years and older in Portugal (21.0\%) [25].
Of relevance, certain health conditions such as hypoalbuminemia, chronic kidney disease, iron deficiency, and cancer in men were associated with increased anemia prevalence rates. In agreement with these findings, Salive et al. reported that, among participants in the Established populations for the Epidemiologic Studies of the Elderly, men and women with hypoalbuminemia were 6.1 and 5.2 as likely to have anemia, respectively [19]. The strong relationship between hypoalbuminemia and anemia has been mediated through the prevalence of chronic disease and nutritional factors [19]. Similarly, chronic kidney disease among older Ecuadorians was also associated with a markedly increased prevalence of anemia in both genders. Bowling et al. using data from the National Health and Nutrition Examination Survey recently described that subjects aged $60-69,70-79$, and 80 years and older with an estimated glomerular filtration rate (eGFR) of $<45 \mathrm{~mL} / \mathrm{min}$ were $3.8,3.2$, and 2 times as likely to have anemia as compared with their counterparts with an eGFR $\geq$ $60 \mathrm{~mL} / \mathrm{min}$, respectively [26]. Despite the strong relationship between decreased eGFR and anemia, chronic kidney disease accounted for a small proportion of older adults with anemia in Ecuador, which is consistent with results from a prior investigation [3].

In Ecuador, one-third of older adults with anemia had evidence of iron and vitamin $B_{12}$ deficiency. Overall, the prevalence of iron deficiency anemia among older Ecuadorians was higher than that reported among older adults in the US and Mexico $[3,23]$. This marked difference in iron deficiency anemia prevalence rates may be partly explained by study methodology differences as a higher ferritin cut-off 
TABLE 3: Prevalence of anemia among older men in Ecuador.

\begin{tabular}{|c|c|c|}
\hline Characteristics & Crude prevalence & OR $(95 \% \mathrm{CI})^{*}$ \\
\hline \multicolumn{3}{|l|}{ Age groups (years), \% } \\
\hline $60-69$ & $19.5(15.1,24.9)$ & 1.00 \\
\hline $70-79$ & $27.9(22.4,34.1)$ & $1.56(1.54,1.59)$ \\
\hline$\geq 80$ & $34.2(26.8,42.6)$ & $1.81(1.78,1.84)$ \\
\hline \multicolumn{3}{|l|}{ Race, \% } \\
\hline Indigenous & $15.6(8.7,26.4)$ & $0.63(0.61,0.65)$ \\
\hline Black & $26.3(14.1,43.9)$ & $1.01(0.97,1.05)$ \\
\hline Mestizo & $26.7(22.6,31.3)$ & $1.16(1.14,1.19)$ \\
\hline Mulatto & $19.5(9.7,35.1)$ & $0.65(0.62,0.68)$ \\
\hline White & $24.9(16.0,36.7)$ & 1.00 \\
\hline \multicolumn{3}{|l|}{ Area of residency, $\%$} \\
\hline Urban Andes Mountains & $23.3(17.8,29.9)$ & $0.94(0.92,0.96)$ \\
\hline Urban coast & $30.4(24.3,37.2)$ & $1.42(1.40,1.45)$ \\
\hline Rural Andes Mountains & $19.3(14.5,25.3)$ & $0.86(0.84,0.88)$ \\
\hline Rural coast & $24.5(17.4,33.5)$ & 1.00 \\
\hline \multicolumn{3}{|l|}{ Literacy, \% } \\
\hline Yes & $23.6(20.0,27.7)$ & 1.00 \\
\hline No & $30.7(23.9,38.7)$ & $1.34(1.32,1.36)$ \\
\hline \multicolumn{3}{|l|}{ Smoking, \% } \\
\hline Current & $24.8(17.5,33.8)$ & $1.12(1.10,1.14)$ \\
\hline Former & $26.2(21.5,31.6)$ & $1.10(1.08,1.11)$ \\
\hline Never & $23.6(18.8,29.2)$ & 1.00 \\
\hline \multicolumn{3}{|l|}{ BMI $\left(\mathrm{kg} / \mathrm{m}^{2}\right), \%$} \\
\hline Underweight & $35.0(18.5,56.1)$ & $1.55(1.48,1.63)$ \\
\hline Normal & $29.5(24.4,35.1)$ & $1.49(1.45,1.52)$ \\
\hline Overweight & $18.7(14.3,24.2)$ & $0.82(0.80,0.84)$ \\
\hline Obesity & $19.0(11.8,29.3)$ & 1.00 \\
\hline \multicolumn{3}{|l|}{ Self-reported health, \% } \\
\hline Excellent to good & $18.2(13.6,23.9)$ & 1.00 \\
\hline Fair to poor & $28.2(24.1,32.7)$ & $1.65(1.62,1.67)$ \\
\hline \multicolumn{3}{|l|}{ ADL's limitations, $\%$} \\
\hline Yes & $36.1(28.8,44.2)$ & $1.71(1.69,1.74)$ \\
\hline No & $22.0(18.5,26.0)$ & 1.00 \\
\hline \multicolumn{3}{|l|}{ Cognitive impairment, $\%$} \\
\hline Yes & $34.6(26.0,44.5)$ & $1.76(1.72,1.79)$ \\
\hline No & $21.9(18.4,25.8)$ & 1.00 \\
\hline \multicolumn{3}{|l|}{ Diabetes } \\
\hline Yes & $25.6(17.7,35.6)$ & $1.04(1.02,1.06)$ \\
\hline No & $25.2(21.7,29.0)$ & 1.00 \\
\hline \multicolumn{3}{|l|}{ Cancer, \% } \\
\hline Yes & $68.0(42.8,85.7)$ & $6.53(6.27,6.80)$ \\
\hline No & $24.2(21.0,27.8)$ & 1.00 \\
\hline \multicolumn{3}{|l|}{ COPD, \% } \\
\hline Yes & $28.6(18.4,41.5)$ & $1.07(1.04,1.10)$ \\
\hline No & $24.9(21.5,28.6)$ & 1.00 \\
\hline \multicolumn{3}{|l|}{ Heart disease, $\%$} \\
\hline Yes & $21.9(14.6,31.7)$ & $0.65(0.64,0.67)$ \\
\hline No & $25.7(22.2,29.6)$ & 1.00 \\
\hline \multicolumn{3}{|l|}{ Arthritis, $\%$} \\
\hline Yes & $29.8(22.5,38.3)$ & $1.29(1.27,1.31)$ \\
\hline No & $24.0(20.5,28.0)$ & 1.00 \\
\hline
\end{tabular}


TABLE 3: Continued.

\begin{tabular}{|c|c|c|}
\hline Characteristics & Crude prevalence & OR $(95 \% \mathrm{CI})^{*}$ \\
\hline \multicolumn{3}{|l|}{ CRP (mg/L), \% } \\
\hline$<5$ & $21.9(18.3,26.0)$ & 1.00 \\
\hline$\geq 5$ & $37.5(30.6,45.0)$ & $2.10(1.24,1.27)$ \\
\hline \multicolumn{3}{|c|}{ Creatinine clearance (mL/min), \% } \\
\hline$>30$ & $23.8(20.5,27.4)$ & 1.00 \\
\hline$\leq 30$ & $57.3(37.8,74.8)$ & $2.98(2.86,3.11)$ \\
\hline \multicolumn{3}{|c|}{ Albumin (g/dL), \% } \\
\hline$\geq 3.5$ & $24.4(21.1,28.0)$ & 1.00 \\
\hline$<3.5$ & $71.1(39.7,90.2)$ & $6.83(6.52,7.16)$ \\
\hline \multicolumn{3}{|c|}{ Vitamin $\mathrm{B}_{12}(\mathrm{ng} / \mathrm{mL}), \%$} \\
\hline$\geq 200$ & $25.7(22.1,29.6)$ & 1.00 \\
\hline$<200$ & $22.7(16.3,30.8)$ & $0.81(0.80,0.83)$ \\
\hline \multicolumn{3}{|c|}{ Ferritin (ng/mL),\% } \\
\hline$<45$ & $43.9(32.5,56.1)$ & $2.78(2.73,2.83)$ \\
\hline$\geq 45$ & $22.6(19.3,26.1)$ & 1.00 \\
\hline \multicolumn{3}{|c|}{ Ferritin (ng/mL), \% } \\
\hline$\leq 200$ & $26.7(22.9,31.0)$ & 1.00 \\
\hline$>200$ & $21.5(15.9,28.5)$ & $0.80(0.79,0.81)$ \\
\hline
\end{tabular}

${ }^{*}$ Adjusted for age, race, area of residency, literacy, and smoking status.

TABLE 4: MCV distribution among older adults with selected causes of anemia in Ecuador.

\begin{tabular}{|c|c|c|c|}
\hline & $\mathrm{MCV}<80 \mathrm{fl}$ & MCV 80-100 fl & $\mathrm{MCV}>100 \mathrm{fl}$ \\
\hline \multicolumn{4}{|c|}{ Men } \\
\hline Total & $7.6(2.3)$ & $87.4(3.0)$ & $5.0(2.2)$ \\
\hline Chronic kidney disease & - & $100.0(0)$ & - \\
\hline Vitamin $B_{12}$ deficiency & $1.7(1.1)$ & $94.3(2.1)$ & $4.0(1.9)$ \\
\hline Iron deficiency & $13.9(11.4)$ & $86.1(4.3)$ & - \\
\hline Chronic disease & $0.5(0.4)$ & $96.3(1.4)$ & $3.2(1.3)$ \\
\hline Low grade inflammation & $1.8(0.9)$ & $96.8(1.2)$ & $1.4(0.7)$ \\
\hline \multicolumn{4}{|c|}{ Women } \\
\hline Total & $10.2(2.4)$ & $88.4(2.5)$ & $1.3(0.7)$ \\
\hline Chronic kidney disease & - & $93.4(4.6)$ & $6.6(4.6)$ \\
\hline Vitamin $B_{12}$ deficiency & $2.6(1.6)$ & $95.3(2.0)$ & $2.2(1.3)$ \\
\hline Iron deficiency & $14.7(3.8)$ & $85.3(3.8)$ & - \\
\hline Chronic disease & $0.7(0.5)$ & $98.4(0.7)$ & $0.9(0.5)$ \\
\hline Low grade inflammation & $5.8(1.8)$ & $93.4(1.8)$ & $0.9(0.5)$ \\
\hline
\end{tabular}

level was used as an indicator of iron deficiency anemia in the present study [14]. While some cases of iron deficiency results from diet, the etiology of iron deficiency anemia in older adults is most likely associated with gastrointestinal lesions. Rockey and Cello demonstrated that, among subjects evaluated for idiopathic iron deficiency anemia, gastrointestinal endoscopy revealed a least one lesion potentially responsible for blood loss in $62 \%$ of cases. The most frequent abnormality in the upper gastrointestinal tract was peptic ulcer and cancer was the most common colonic lesion [27]. In Ecuador, it may be postulated that the increased prevalence of anemia found among older men diagnosed with cancer may be associated with iron, vitamin $\mathrm{B}_{12}$ deficiency, and chronic inflammation. Indeed, previous research has shown that both atrophic gastritis and $H$. pylori infection may result in vitamin $\mathrm{B}_{12}$ and iron deficiency $[28,29]$. Similarly, these gastric pathologies increase considerably the risk of gastric cancer $[30,31]$. Despite this evidence, further research is needed to confirm these associations. Moreover, the increased prevalence of vitamin $B_{12}$ deficiency among older men in Ecuador is consistent with results from previous investigations reporting higher vitamin $B_{12}$ deficiency prevalence rates among older men in the US and Chile $[32,33]$. In Ecuador, the reasons for the gender difference in vitamin $B_{12}$ concentrations are unknown. However, vitamin $B_{12}$ dietary sources and supplements, which were not examined in the present study, may partly explain this finding. Of clinical relevance, only $3 \%$ of older Ecuadorians with vitamin $\mathrm{B}_{12}$ deficiency had evidence 
of macrocytic anemia. Likewise, Loikas et al. demonstrated in a population-based study among older from Finland that the presence of macrocytosis or macrocytic anemia did not increase the odds of having vitamin $\mathrm{B}_{12}$ deficiency, which is consistent with the present results [34].

Interestingly, one-third of older Ecuadorians with anemia had evidence of low grade inflammation. Nonnutritional anemia in older adults has been documented to result from an interaction between an increased inflammatory milieu and age-related comorbidities. Among the inflammatory markers, IL-6 leads to iron-limited hematopoiesis with increased hepcidin levels and poor iron incorporation into the developing erythrocytes. In addition, tumor necrosis factor $\alpha$, in a different pathway, leads to erythropoietin resistance of the hematopoietic stem cells, increasing its demand and eventually exceeding the ability of the kidney to maintain adequate levels to sustain normal hemoglobin [15].

The present study has several limitations that should be mentioned. First, because of the cross-sectional study design, the association of anemia with certain demographic and health characteristics does not necessarily indicate causation. Second, the evaluation of nutritional and nonnutritional anemia should be considered preliminary. For instance, iron and vitamin $\mathrm{B}_{12}$ anemia were defined exclusively according to ferritin and vitamin $B_{12}$ levels available in the SABE survey, respectively. Moreover, other potential causes of anemia affecting older adults such as folate deficiency and myelodysplastic syndromes requiring cytogenetic and bone marrow analyses were not evaluated in the present study [34]. Third, most of the participant's comorbidities and lifestyle variables were self-reported, which may be a source of recall bias. Fourth, the present findings may be only generalized to older adults residing in the coastal and Andes Mountains regions of the country. Despite these limitations, the present study reports national estimates of anemia among older adults.

In conclusion, anemia is a prevalent condition among older adults in Ecuador. Moreover, further research is needed to examine the association between anemia and adverse health-related outcomes among older Ecuadorians.

\section{Competing Interests}

The author declares that there is no conflict of interests regarding the publication of this paper.

\section{References}

[1] D. Lipschitz, "Medical and functional consequences of anemia in the elderly," Journal of the American Geriatrics Society, vol. 51, no. 3, pp. S10-S13, 2003.

[2] B. W. J. H. Penninx, M. Pahor, R. C. Woodman, and J. M. Guralnik, "Anemia in old age is associated with increased mortality and hospitalization," Journals of Gerontology, Series A: Biological Sciences and Medical Sciences, vol. 61, no. 5, pp. 474479, 2006.

[3] J. M. Guralnik, R. S. Eisenstaedt, L. Ferrucci, H. G. Klein, and R. C. Woodman, "Prevalence of anemia in persons 65 years and older in the United States: evidence for a high rate of unexplained anemia," Blood, vol. 104, no. 8, pp. 2263-2268, 2004.

[4] H. Gaskell, S. Derry, R. Andrew Moore, and H. J. McQuay, "Prevalence of anaemia in older persons: systematic review," BMC Geriatrics, vol. 8, article no. 1, 2008.

[5] L. Ferrucci, R. D. Semba, J. M. Guralnik et al., "Proinflammatory state, hepcidin, and anemia in older persons," Blood, vol. 115, no. 18, pp. 3810-3816, 2010.

[6] W. B. Freire, K. M. Silva-Jaramillo, M. J. Ramírez-Luzuriaga, P. Belmont, and W. F. Waters, "The double burden of undernutrition and excess body weight in Ecuador," The American Journal of Clinical Nutrition, vol. 100, no. 6, pp. 1636S-1643S, 2014.

[7] C. Cañizares, R. Bonilla, and C. Vásquez, "Prevalence of different types of anemia in Ecuador," Brazilian Journal of Medical and Biological Research, vol. 21, no. 4, pp. 767-772, 1988.

[8] http://www.eclac.cl/celade/proyecciones/basedatos_BD.htm.

[9] http://www.ecuadorencifras.gob.ec/encuesta-de-salud-bienestar-del-adulto-mayor/

[10] M. G. Icaza and C. Albala, Minimental State Examinations (MMSE) del studio de la demencia en Chile: Análisis Estadístico-Serie Investigaciones en Salud Pública-Documentos Técnicos, Coordinación de Investigaciones, División de Salud y Desarrollo Humano, OPS, 1999, http://www.paho.org.

[11] A. Menke, S. Casagrande, L. Geiss, and C. C. Cowie, "Prevalence of and trends in diabetes among adults in the United States, 1988-2012," JAMA, vol. 314, no. 10, pp. 1021-1029, 2015.

[12] http://apps.who.int/iris/bitstream/10665/85839/3/WHO_NMH_ NHD_MNM_11.1_eng.pdf.

[13] M. H. Bross, K. Soch, and T. Smith-Knuppel, "Anemia in older persons," American Family Physician, vol. 82, no. 5, pp. 480-487, 2010.

[14] G. H. Guyatt, C. Patterson, M. Ali et al., "Diagnosis of irondeficiency anemia in the elderly," The American Journal of Medicine, vol. 88, no. 3, pp. 205-209, 1990.

[15] N. Berliner, "Anemia in the elderly," Transactions of the American Clinical and Climatological Association, vol. 124, pp. 230237, 2013.

[16] G. Weiss and L. T. Goodnough, "Anemia of chronic disease," The New England Journal of Medicine, vol. 352, no. 10, pp. 1011-1023, 2005.

[17] D. W. Cockcroft and M. H. Gault, "Prediction of creatinine clearance from serum creatinine," Nephron, vol. 16, no. 1, pp. 3141, 1976.

[18] W. P. J. Den Elzen, J. Gussekloo, J. M. Willems et al., "Predictive value of low ferritin in older persons with anemia with and without inflammation: the Leiden 85-plus study," Journal of the American Geriatrics Society, vol. 58, no. 8, pp. 1601-1603, 2010.

[19] M. E. Salive, J. Cornoni-Huntley, J. M. Guralnik et al., "Anemia and hemoglobin levels in older persons: relationship with age, gender, and health status," Journal of the American Geriatrics Society, vol. 40, no. 5, pp. 489-496, 1992.

[20] Y. Domínguez, C. Zurita, D. Calvopiña, J. Villacís, and M. Mora, "Prevalence of common hemoglobin variants in an afrodescendent Ecuadorian population," BMC Research Notes, vol. 6, no. 1, article no. 132, 2013.

[21] W.-H. Pan and J.-P. Habicht, "The non-iron-deficiency-related difference in hemoglobin concentration distribution between blacks and whites and between men and women," American Journal of Epidemiology, vol. 134, no. 12, pp. 1410-1416, 1991.

[22] B. W. J. H. Penninx, M. Pahor, M. Cesari et al., "Anemia is associated with disability and decreased physical performance 
and muscle strength in the elderly," Journal of the American Geriatrics Society, vol. 52, no. 5, pp. 719-724, 2004.

[23] A. Contreras-Manzano, V. de la Cruz, S. Villalpando, R. Rebollar, and T. Shamah-Levy, "Anemia and iron deficiency in Mexican elderly population. Results from the Ensanut 2012," Salud Publica de Mexico, vol. 57, no. 5, pp. 394-402, 2015.

[24] R. M. Bryce, A. Salas, D. Acosta et al., "The prevalence, correlates and impact of anaemia among older people in Cuba, Dominican Republic, Mexico, Puerto Rico and Venezuela," British Journal of Haematology, vol. 160, no. 3, pp. 387-398, 2013.

[25] C. Fonseca, F. Marques, A. Robalo Nunes, A. Belo, D. Brilhante, and J. Cortez, "Prevalence of anaemia and iron deficiency in Portugal: the EMPIRE study," Internal Medicine Journal, vol. 46, no. 4, pp. 470-478, 2016.

[26] C. B. Bowling, L. A. Inker, O. M. Gutiérrez et al., "Age-specific associations of reduced estimated glomerular filtration rate with concurrent chronic kidney disease complications," Clinical Journal of the American Society of Nephrology, vol. 6, no. 12, pp. 2822-2828, 2011.

[27] D. C. Rockey and J. P. Cello, "Evaluation of the gastrointestinal tract in patients with iron-deficiency anemia," New England Journal of Medicine, vol. 329, no. 23, pp. 1691-1695, 1993.

[28] G. Campuzano-Maya, "Hematologic manifestations of Helicobacter pylori infection," World Journal of Gastroenterology, vol. 20, no. 36, pp. 12818-12838, 2014.

[29] S. P. Stabler, "Vitamin B12 deficiency," New England Journal of Medicine, vol. 368, no. 2, pp. 149-160, 2013.

[30] G. Murphy, S. M. Dawsey, E. A. Engels et al., "Cancer risk after pernicious anemia in the US Elderly population," Clinical Gastroenterology and Hepatology, vol. 13, no. 13, pp. 2282.e42289.e4, 2015.

[31] N. Uemura, S. Okamoto, S. Yamamoto et al., "Helicobacter pylori infection and the development of gastric cancer," New England Journal of Medicine, vol. 345, no. 11, pp. 784-789, 2001.

[32] R. Carmel, R. Green, D. W. Jacobsen, K. Rasmussen, M. Florea, and C. Azen, "Serum cobalamin, homocysteine, and methylmalonic acid concentrations in a multiethnic elderly population: ethnic and sex differences in cobalamin and metabolite abnormalities," American Journal of Clinical Nutrition, vol. 70, no. 5, pp. 904-910, 1999.

[33] M. Olivares, E. Hertrampf, M. T. Capurro, and D. Wegner, "Prevalence of anemia in elderly subjects living at home: role of micronutrient deficiency and inflammation," European Journal of Clinical Nutrition, vol. 54, no. 11, pp. 834-839, 2000.

[34] S. Loikas, P. Koskinen, K. Irjala et al., "Vitamin B12 deficiency in the aged: A Population-Based Study," Age and Ageing, vol. 36, no. 2, pp. 177-183, 2007. 


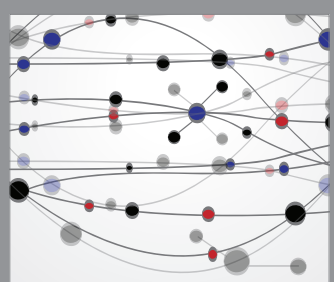

The Scientific World Journal
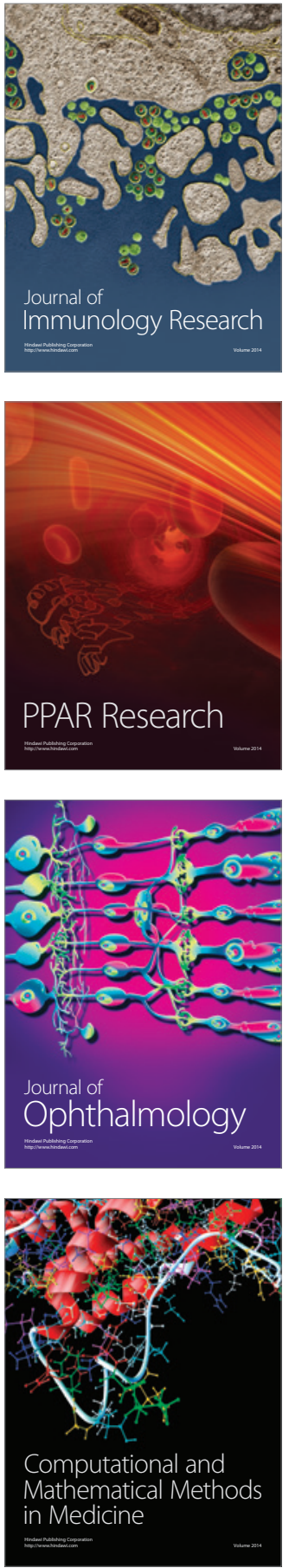

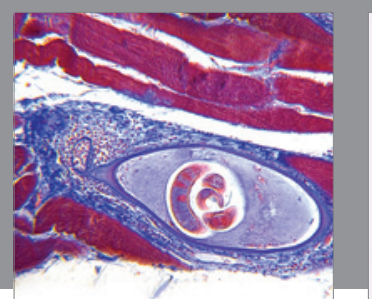

Gastroenterology Research and Practice
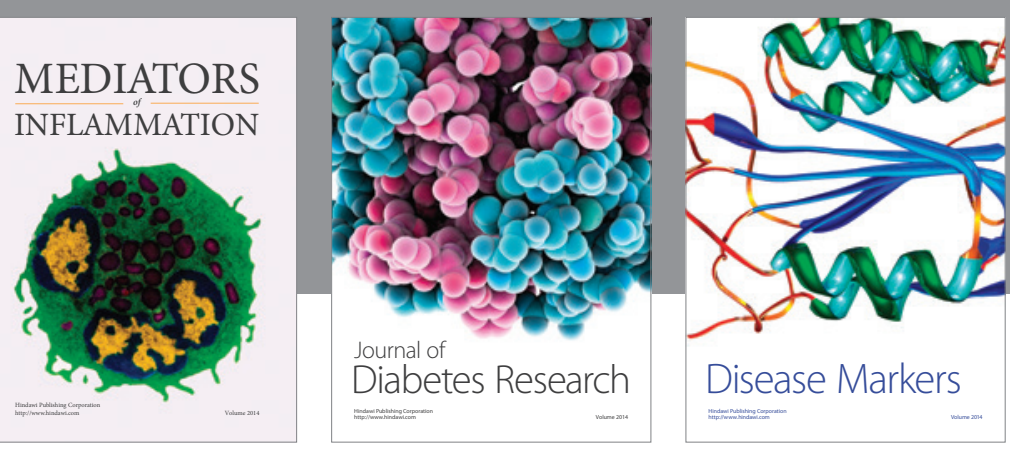

Disease Markers

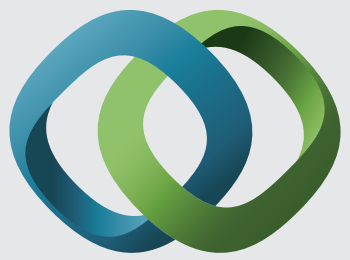

\section{Hindawi}

Submit your manuscripts at

https://www.hindawi.com
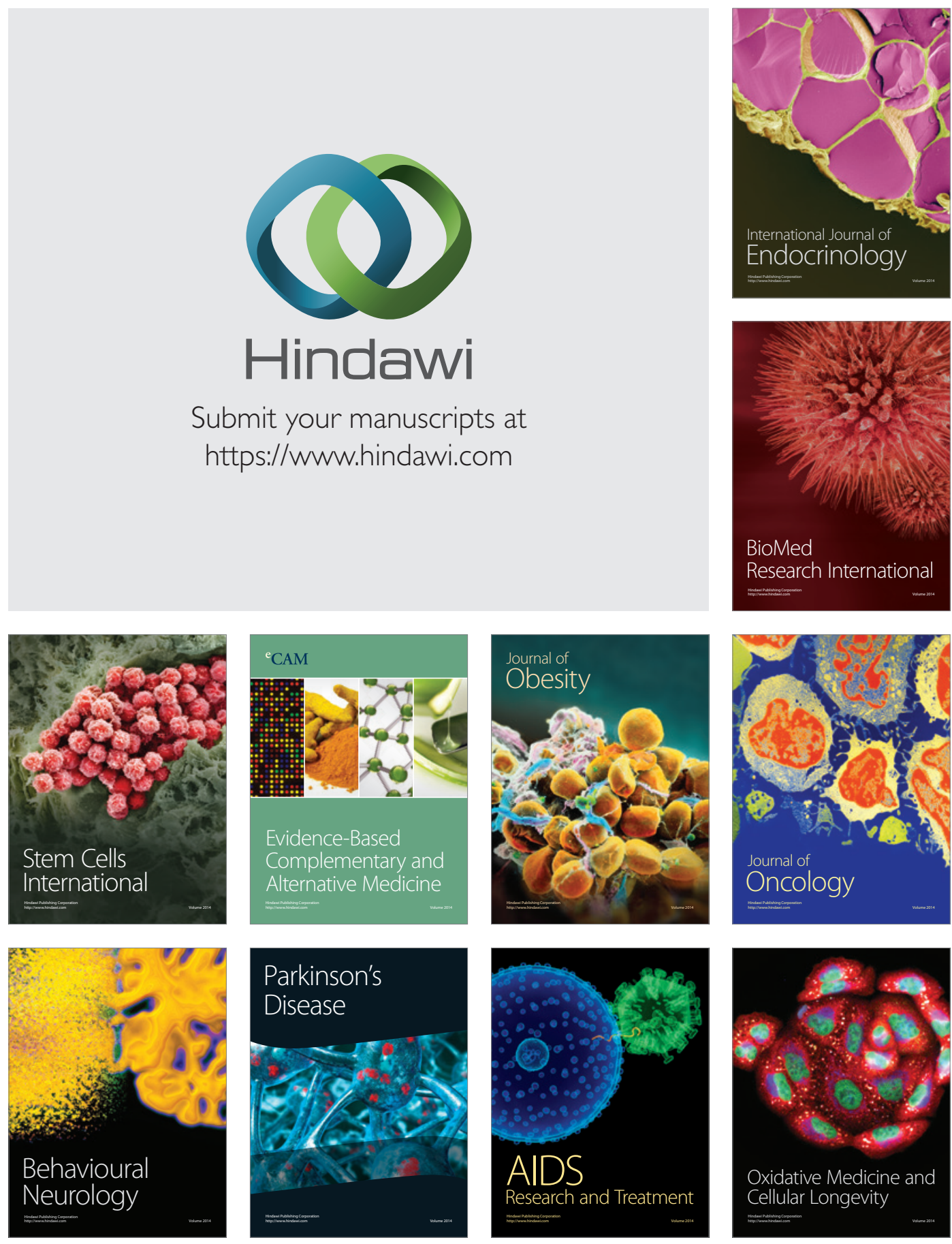